\title{
Performance evaluation of an enzymatic spectrophotometric method for milk urea nitrogen
}

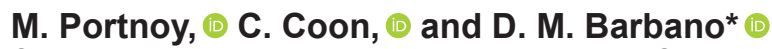

Cornell University, Northeast Dairy Foods Research Center, Department of Food Science, Cornell University, Ithaca, NY 14853

\begin{abstract}
Our objective was to determine the within and between laboratory performance of an enzymatic spectrophotometric method for milk urea nitrogen (MUN) determination. This method first uses urease to hydrolyze urea into ammonia and carbon dioxide. Next, ammonia (as ammonium ions) reacts with 2-oxoglutarate, in the presence of reduced nicotinamide-adenine dinucleotide phosphate (NADPH) and the enzyme glutamate dehydrogenase $(\mathrm{GIDH})$, to form L-glutamic acid, water, and $\mathrm{NADP}^{+}$. The change in light absorption at 340 $\mathrm{nm}$ due to the conversion of NADPH to NADP+ is stoichiometrically a function of the MUN content of a milk sample. The relative within $\left(\mathrm{RSD}_{\mathrm{r}}\right)$ and between $\left(\mathrm{RSD}_{\mathrm{R}}\right)$ laboratory method performance values for the MUN enzymatic spectrophotometric method were $0.57 \%$ and $0.85 \%$, respectively, when testing individual farm milks. The spectrophotometric MUN method demonstrated better within and between laboratory performance than the International Dairy Federation differential $\mathrm{pH}$ MUN method with a much lower $\mathrm{RSD}_{\mathrm{r}}$ (0.57 vs. $1.40 \%$ ) and $\mathrm{RSD}_{\mathrm{R}}$ (0.85 vs. $4.64 \%$ ). The spectrophotometric MUN method also had similar method performance statistics as other AOAC International official validated chemical methods for primary milk component determinations, with the average of all $\mathrm{RSD}_{\mathrm{r}}$ and $\mathrm{RSD}_{\mathrm{R}}$ values being $<1 \%$. An official collaborative study of the enzymatic spectrophotometric MUN method is needed to achieve International Dairy Federation, AOAC International, and International Organization for Standardization official method status.
\end{abstract}

Key words: infrared milk analyzer, calibration, milk urea nitrogen (MUN)

\section{INTRODUCTION}

Urea is a minor milk component that is present in low concentration. In dairy cows, and mammals in gen-

Received February 15, 2021.

Accepted June 22, 2021

*Corresponding author: dmb37@cornell.edu eral, urea is the primary form of nitrogen excretion. Urea is present in both blood and milk. When urea content of blood is high, urea content of milk is also high. Management of dietary nitrogen utilization by dairy cows can have significant economic benefits for the dairy farmer, due to improved reproductive efficiency (Ferguson and Chalupa, 1989; Larson et al., 1997; Rajala-Schultz et al., 2001), efficient use of dietary protein to support milk protein production, and reduced dairy farm environmental effects due to excretion of urea in urine of dairy cows (Kohn et al., 1997; Guo et al., 2004; Mitchell et al., 2005). Blood urea nitrogen has been proven to be a useful indicator of the efficiency of protein nitrogen utilization in ruminants (Lewis, 1957); however, blood sample collection is an invasive procedure and causes stress to the animals. A less invasive alternative to BUN measurements is measurement of MUN. The MUN is highly correlated with BUN, and closely related to $\mathrm{CP}$ concentrations in diets (Broderick and Clayton, 1997; Nousiansen et al., 2004). In fact, MUN is also highly correlated with urinary nitrogen in dairy cows (Ciszuk and Gebregziabher, 1994; Kauffman and St-Pierre, 2001, Spek et al., 2013, 2016). Therefore, measuring MUN provides a method to monitor overall nitrogen utilization efficiency, as milk samples are routinely collected for payment testing and dairy herd monitoring.

A fast and efficient way to measure MUN is with a mid-infrared (MIR) milk analyzer. These instruments rely on the relationship between absorbance by milk component molecules and their concentrations in milk (Goulden, 1964). Fat, protein, and lactose are determined by fixed filter wavelengths (Kaylegian et al., 2009), where a sample wavelength and a reference wavelength exist for each of these 3 milk components. Other minor milk components, such as MUN, are most commonly determined using partial least squares prediction models using absorbance at multiple wavelengths in the MIR milk spectra (Haaland and Thomas, 1988). However, milk MIR determination of MUN is a secondary method that requires calibration with samples that have known MUN values based on analysis with a chemical reference method. Examples of reference methods with 
high accuracy, repeatability, and reproducibility used to obtain reference values for the calibration of fat, protein, and lactose measurement by MIR are Mojonnier ether extraction for milk fat (Barbano et al., 1988; AOAC International, 2019c; method 989.05), Kjeldahl direct method for true protein nitrogen determination (Barbano et al., 1991; AOAC International, 2019c; method 991.22), and the spectrophotometric enzymatic analysis for milk lactose (Lynch et al., 2007; AOAC International, 2019c; method 2006.06), respectively. Therefore, an accurate reference chemical method for the determination of MUN is necessary for calibration of MIR instruments.

The MUN enzymatic spectrophotometric method is currently used in the USDA Federal Milk Market laboratories as the reference method for the calibration of infrared instruments for the determination of MUN. The objective of the current study was to determine the within and between laboratory performance of an enzymatic spectrophotometric method for MUN determination.

\section{MATERIALS AND METHODS}

\section{MUN Enzymatic Spectrophotometric Method}

Principle. Milk fat and protein must be precipitated and removed from the milk to obtain a clear solution before the spectrophotometric assay. The enzymatic method for quantifying MUN used in our study is based on 2 enzymatic reactions. In the first reaction, urea and water form ammonia and carbon dioxide in the presence of the enzyme urease. In the second reaction, ammonia (as ammonium ions) reacts with 2-oxoglutarate, in the presence of reduced nicotinamide-adenine dinucleotide phosphate (NADPH) and the enzyme glutamate dehydrogenase (GIDH), to form L-glutamic acid, water, and $\mathrm{NADP}^{+}$. The molecule that absorbs during the spectrophotometric measurement at $340 \mathrm{~nm}$ is NADPH. Using Beer's Law, with the difference of absorption before and after the reactions have taken place, the amount of NADPH that was consumed can be determined. The amount of NADPH consumed is directly proportional to the amount of urea that was present in the milk sample and can be calculated stoichiometrically using the extinction coefficient for NADPH and the molecular weight of urea. Milk urea nitrogen is calculated as urea multiplied by 0.46646 . The reagents used in the urea standard solution preparation and enzymatic assay were premade from the Megazyme Urea/ Ammonia Assay Kit (Rapid) (Megazyme, product code K-URAMR).

Urea Standard Solution Preparation. A reference standard urea solution [of approximately $0.007 \%$
(\% wt/wt)] was prepared in one laboratory and distributed to all laboratories with the milk samples. The MUN reference solution was prepared as follows: 0.07 $\mathrm{g}$ of urea (Bottle 5 from Megazyme kit: Urea Control Powder) was weighed into a plastic weighing boat (Dyn-A-Med \#80051), using an analytical balance (Mettler Toledo AT400). The urea was transferred to a 1-L class A volumetric flask, and the empty boat was reweighed. The transferred amount of urea was determined [(weight of boat and urea) - (weight of empty boat)]. The weight of the volumetric flask with urea was then tared on an analytical balance (Mettler Toledo PG5002-S) and distilled water was added to the mark at $20^{\circ} \mathrm{C}$. The previously tared flask was weighed to obtain the weight of water added. The solution was mixed by inversion and portioned into $45-\mathrm{mL}$ plastic vials (Aptar CSP Technologies, \#CPP02CL) to send to the different laboratories. The concentration (\% wt/ wt) of the urea standard solution was determined by dividing the weight of transferred urea by the weight of water added.

Milk Sample Preparation. About 5 g of milk was weighed into a previously weighed 125 -mL Erlenmeyer flask using a balance readable to $0.1 \mathrm{mg}$ (Mettler Toledo model AX304) with the capacity to accommodate the final solution weight $(\sim 20 \mathrm{~g})$ and container. The weight of milk added to the flask [(weight of flask with milk) minus (weight of flask)] was determined $\left(\mathrm{W}_{\mathrm{m}}\right)$. Next, $15 \mathrm{~mL}$ of a $0.3 \mathrm{M}$ solution of trichloroacetic acid (Sigma-Aldrich, T6399-500G) was added, using 3 additions from a 5-mL bottle-top dispenser (Brinkmann Dispensette), to the solution and mixed by swirling. The flask and its contents were immediately weighed, and the weight of the contents in the flask [(weight of flask with all contents) minus (weight of flask)] was determined $\left(\mathrm{W}_{\mathrm{p}}\right)$. The contents of the flask were then filtered through a fluted filter paper (Whatman \#1, M $15 \mathrm{~cm}$ ) and the filtrate collected in a 125-mL Erlenmeyer flask. If the filtrate was not clear, the sample preparation was repeated. For duplicate spectrophotometric analysis of a milk, 2 milk test portions and 2 filtrations were done. After the filtrate was collected, about $1 \mathrm{~mL}$ was pipetted into a capped $1.5-\mathrm{mL}$ flex tube (Eppendorf, Safe-Lock Tubes \#022363204) and stored at $4^{\circ} \mathrm{C}$. The assay was run within $4 \mathrm{~h}$ of the test sample preparation.

Enzymatic Assay. The refrigerated filtrate and reagent solutions were brought to 19 to $23^{\circ} \mathrm{C}$ and mixed by swirling to ensure uniformity. Disposable plastic cuvettes with nominal 1-cm light path (2.5-mL disposable cuvettes) in boxes of 100 (BrandTech, \#759070D) were obtained from one supplier and a relative path length correction for each 100-cuvette batch was determined as described by Lynch et al. (2007). Cuvettes 
were matched by the manufacturer's mold identification to minimize deviation in path length between cuvettes within a single analysis session. One labeled cuvette and labeled cap (Fisher Scientific, \#14385999) were used for each filtrate. The cuvette and cap were weighed $\left(\mathrm{W}_{\mathrm{c}}\right.$; to the nearest $0.1 \mathrm{mg}$ ) using the same balance as for the milk preparation (0.1 $\mathrm{mg}$, Mettler Toledo, AX304). Then, $0.1 \mathrm{~mL}$ of the sample filtrate was pipetted using an air displacement pipette (Gilson, Pipetman P100) into the bottom of the cuvette and immediately weighed $\left(\mathrm{W}_{\mathrm{i}}\right)$ again with the cap. Next, the following solutions were pipetted into the cuvette in this specific order: $2.00 \mathrm{~mL}$ of distilled water using an air displacement pipette (Gilson, Pipetman P5000), $0.30 \mathrm{~mL}$ of buffer solution [Bottle 1 from Megazyme kit: buffer $\mathrm{pH}$ 8.0, plus 2-oxoglutarate and sodium azide $(0.02 \% \mathrm{wt} / \mathrm{vol})]$ using an air displacement pipette (Mettler-Toledo Rainin, Classic PR-1000), $0.20 \mathrm{~mL}$ of NADPH (Bottle 2 from Megazyme kit) using an air displacement pipette (Gilson, Pipetman P200), and $0.02 \mathrm{~mL}$ of GlDH suspension (Bottle 3 from Megazyme kit) using a positive placement pipette (Gilson, Microman M25). The glutamate dehydrogenase solution was added to the side of the cuvette with caution to not immerse the tip of the pipet in the liquid in the cuvette. There was no weighing in between or at the end of any of these additions. The cuvette was then capped securely and its contents mixed gently by inversion. After a minimum of $5 \mathrm{~min}$, absorbance of the solution in each cuvette at $340 \mathrm{~nm}$ (UV/vis Spectrophotometer, Shimadzu Corp., UV-1800 120V) was determined. The spectrophotometer was zeroed on air, and the first absorbance measurement (A1) was read. If reading multiple cuvettes, the zero was monitored and re-zeroed as necessary.

After the first absorbance reading, $0.05 \mathrm{~mL}$ of urease solution (Bottle 4 from Megazyme kit) was added using an air displacement pipette (Gilson, Pipetman P100) to the cuvette by gently removing one corner of the cap on the cuvette and pipetting the urease solution, taking care to not lose any of the cuvette solution in the process. The cuvette was then recapped immediately. Each cuvette was mixed by inversion and held at 19 to $23^{\circ} \mathrm{C}$ for $10 \mathrm{~min}$. The cuvette with cap was reweighed $\left(\mathrm{W}_{\mathrm{t}}\right)$, and a second absorbance reading (A2) was taken after the cuvette was incubated at 19 to $23^{\circ} \mathrm{C}$ (room temperature) for $10 \mathrm{~min}$. The orientation of each cuvette in the spectrophotometer light beam was kept the same for both the A1 and A2 readings for both blank and sample cuvettes. Duplicates of each milk sample were prepared and analyzed.

Two test portions of the urea reference standard solution were run each time a batch of samples were run through the assay by substituting $0.1 \mathrm{~mL}$ of the urea standard solution for the filtrate in the determination. Two reagent blanks were run each time the assay was conducted by substituting $0.1 \mathrm{~mL}$ of distilled water for the filtrate in the determination. For the multiple solution additions during the enzymatic assay, if working with multiple cuvettes, the addition of one solution was made to all the cuvettes and all cuvettes were weighed where the procedure indicates; then, the next solution was added to all the cuvettes, and so forth, instead of adding all the solutions to one cuvette and then doing the same to each of the other cuvettes.

Calculating the Weight of Sample Filtrate and Final Contents of the Cuvette. The following calculations were done to determine the weight of the sample filtrate and final contents of the cuvette, where $W_{f}=$ weight, g, of filtrate added to cuvette; $W_{i}=$ weight, $\mathrm{g}$, of cuvette containing the filtrate; $W_{c}=$ weight, $\mathrm{g}$, of empty cuvette; $W_{s}=$ total weight, g, of final contents of the cuvette; $W_{t}=$ weight, $\mathrm{g}$, of cuvette containing all assay additions:

$$
\begin{gathered}
W_{f}=W_{i}-W_{c}, \text { and } \\
W_{s}=W_{i}-W_{c} .
\end{gathered}
$$

Calculating the Average Absorbance of the Blanks. The following calculation was done to get the average absorbance of the blanks, where $B=$ average absorbance of the blanks; $A 2_{\text {blank } 1}=$ absorbance of the first blank after the addition of urease; $A 1_{\text {blank } 1}=$ absorbance of the first blank before the addition of urease, $A 2_{\text {blank } 2}=$ absorbance of the second blank after the addition urease; and $A 1_{\text {blank } 2}=$ absorbance of the second blank before the addition of urease:

$$
B=\frac{\left(A 1_{\text {blank } 1}-A 2_{\text {blank } 1}\right)+\left(A 1_{\text {blank } 2}-A 2_{\text {blank } 2}\right)}{2} .
$$

Calculating Urea Concentration. The following calculation was done to determine the urea concentration, where $W_{m}=$ weight $(\mathrm{g})$ of milk sample minus weight of the $125 \mathrm{~mL}$ Erlenmeyer flask; $W_{p}=$ weight (g) of total milk sample preparation solution minus weight of the $125 \mathrm{~mL}$ Erlenmeyer flask; $W_{f}=$ weight (g) of filtrate added to cuvette; $W_{s}=$ total weight (g) of final contents of the cuvette; $A 1=$ absorbance value 1; $A 2$ = absorbance value 2 ; $B=$ average blank absorbance value; $60.0553=$ molecular weight $(\mathrm{g} / \mathrm{mol}$, of urea); $6.3=$ extinction coefficient of NADPH at 340 $\mathrm{nm}\left(\mathrm{L} \times \mathrm{mmol}^{-1} \times \mathrm{cm}^{-1}\right) ; P=$ adjustment to correct for path length of disposable cuvettes from a single box 
(determined separately for each box of cuvettes); $2=$ stoichiometric factor $(2$ moles of NADPH are consumed for each mole of urea); $10=$ conversion factor from $\mathrm{mL}$ to $\mathrm{L}$, mmol to mol, $\mathrm{g}$ to $\mathrm{mg}$, and to obtain urea/100 g of milk; and $1.0034=$ density $(\mathrm{g} / \mathrm{mL})$ of the final assay solution:

$$
\text { Urea }(\mathrm{mg} / 100 \mathrm{~g})=\frac{\left(\frac{W_{s}}{1.0034}\right) \times 60.0553}{6.3 \times W_{f} \times P \times 10 \times 2} \times(A 1-A 2-B) \times \frac{W_{p}}{W_{m}}
$$

A density of $1.0034 \mathrm{~g} / \mathrm{mL}$ is used as the density of the assay solution in the cuvette. This density was calculated from the density value of the solution in the cuvette in the enzymatic spectrophotometric method for lactose (AOAC International, 2019c, method 2006.06; Lynch et al., 2007). The lactose method has very a similar principle, procedure, and equipment to the MUN method described here, but the density value for the cuvette assay solution in the lactose method was measured and resulted in $1.0049 \mathrm{~g} / \mathrm{mL}$. The solute concentration of the cuvette assay solutions in the MUN and lactose methods were calculated, and their ratio was used to adjust the density value for the MUN method. This resulted in the density change from $1.0049 \mathrm{~g} / \mathrm{mL}$ (for the lactose procedure) to $1.0034 \mathrm{~g} / \mathrm{mL}$ (for the MUN procedure).

Calculating Milk Urea Nitrogen. Based on the molecular structure of urea, the nitrogen content of urea is $46.646 \%$ by weight. Therefore, the following calculation was done to calculate MUN concentration, where Urea $=$ urea $(\mathrm{mg} / 100 \mathrm{~g})$ :

$$
\operatorname{MUN}(\mathrm{mg} / 100 \mathrm{~g})=\text { Urea } \times 0.46646 .
$$

\section{Performance Evaluation of the Enzymatic Spectrophotometric MUN Method}

Modified Milk Calibration Sample Set to Evaluate Method Performance. Modified milk calibration samples (14 milk samples per set), prepared in the Cornell University Pilot Plant as described by Kaylegian et al. (2006), and as modified by Portnoy et al. (2021), were shipped to a total of 9 laboratories, where they were analyzed by reference chemical methods for all the main milk components and MUN. The methods used to determine fat, protein, and lactose in the sample set were the following validated methods (AOAC International, 2019c): for fat, Mojonnier ether extraction (Barbano et al., 1988; AOAC International, 2019c; method 989.05); for true protein, Kjeldahl analysis for direct protein nitrogen determination (Barbano et al., 1991; AOAC International, 2019c; method 991.22); for lactose, spectrophotometric enzymatic analysis (Lynch et al., 2007; AOAC International, 2019c; method 2006.06). The MUN was determined by the enzymatic spectrophotometric method described above. The modified milk set of samples, analyzed by all laboratories, provided the opportunity to evaluate the analytical performance of the MUN enzymatic spectrophotometric method within and between laboratories, using the same approach described by Wojciechowski et al. (2016). The samples also provided a calibration milk sample set to obtain reference method all-laboratory mean values for each component for the calibration of milk infrared instruments (Kaylegian et al., 2006). Analytical performance statistics and individual laboratory diagnostics were determined for the MUN enzymatic spectrophotometric method using the results from several months of the group of laboratories running this modified milk calibration sample set.

Blind-Coded, Raw Milk Sample Set to Evaluate Method Performance. The same analytical method for MUN measurement and group of laboratories analyzed a set of 8 blind-duplicate coded (i.e., 16 vials of milk), raw individual farm milks from different parts of the United States. The sample ID coding was different for every laboratory, so no 2 laboratories had samples with the same identification codes. Method performance statistics for within and between laboratory method performance and individual laboratory performance were determined using the MUN enzymatic spectrophotometric method results from various months where the group of laboratories ran the farm milk sample set, to compare the performance of this MUN chemical method when applied to farm milk and to modified milk calibration samples.

Statistical Analysis. For performance statistical analysis of the MUN enzymatic spectrophotometric method, the AOACI statistical procedures were used to determine within laboratory statistics, referring to the method repeatability $\left(\mathrm{s}_{\mathrm{r}}, \mathrm{RSD}_{\mathrm{r}}, \mathrm{r}\right.$-value), as well as between laboratory statistics, referring to the method reproducibility $\left(\mathrm{s}_{\mathrm{R}}, \mathrm{RSD}_{\mathrm{R}}, \mathrm{R}\right.$-value). The meaning and relevance of each of these values is explained by Lynch (1998). The Microsoft Excel AOAC Interlaboratory Statistical Program, version 1.11 (Microsoft Corp.), was used to calculate these statistics and identify outliers following the guidelines for interlaboratory studies of AOAC International (2019a), as performed by Wojciechowski et al. (2016). Statistical outliers were identified using the Cochran, single Grubbs and double Grubbs tests with a significance level of $2.5 \%$ (Wojciechowski et al., 2016). 


\section{RESULTS AND DISCUSSION}

\section{Within- and Between-Laboratory Performance of the MUN Enzymatic Spectrophotometric Method}

The enzymatic method performance statistics and MUN results summary for known duplicate analysis of each of the 14 individual modified milk samples made each month for the first 9 mo of 2019 are shown in Table 1. The number of labs testing ranged from 7 to 9 labs from one month to another, depending on the availability of a technician that month. The low to high range of MUN concentration was from about 11 to $23 \mathrm{mg}$ of MUN/100 g of milk. Before calculation of method performance statistics, statistical outliers were removed as described by Wojciechowski et al. (2016). The number of statistical outlier data points per month was $10 \%$ of the total tests in that month. Typically, when the number of statistical outliers was high in a month, they were predominantly from one laboratory that was having an analytical problem that month. The average relative within-laboratory repeatability $\left(\mathbf{R S D}_{\mathbf{r}}\right)$ was $0.46 \%$ and the average between-laboratory reproducibility $\left(\mathbf{R S D}_{\mathbf{R}}\right)$ was $0.87 \%$ of the mean MUN concentration for the modified milk calibration samples. The frequency of statistical outliers for measurement of fat, protein, and lactose on these samples was comparable to that for MUN and the values are presented in a footnote in Table 1

The spectrophotometric MUN method performance statistics for analysis of 3 blind-duplicate coded, individual bulk tank raw milk sets made in 2019 are shown in Table 2. The $\mathrm{RSD}_{\mathrm{r}}$ was $0.57 \%$ and the $\mathrm{RSD}_{\mathrm{R}}$ was $0.85 \%$ of the mean MUN concentration for the individual farm milk samples and was very comparable to the results on the modified milk calibration samples. The Horwitz value (Horwitz et al., 1998) is a calculated value for analytical method performance using the $\mathrm{RSD}_{\mathrm{R}}$ values for many analytical methods to describe the relationship between analyte concentration and expected between laboratory analytical performance (called the Horwitz trumpet). Based on the Horwitz trumpet relationship, any method that has a relative within and between laboratory variation $<1 \%$ of the analyte concentration is considered to be a method with excellent analytical performance (AOAC International, 2019b).

Method performance statistics for other reported MUN determination methods (Oltner et al., 1985; Andersson et al., 1986; De Jong et al., 1992; Luzzana and Giardino 1999; Baumgartner et al., 2002; IDF, 2004) and the enzymatic spectrophotometric method (current study) are compared in Table 3. Overall, the enzymatic spectrophotometric method described in the current study had better repeatability and reproducibility (low-

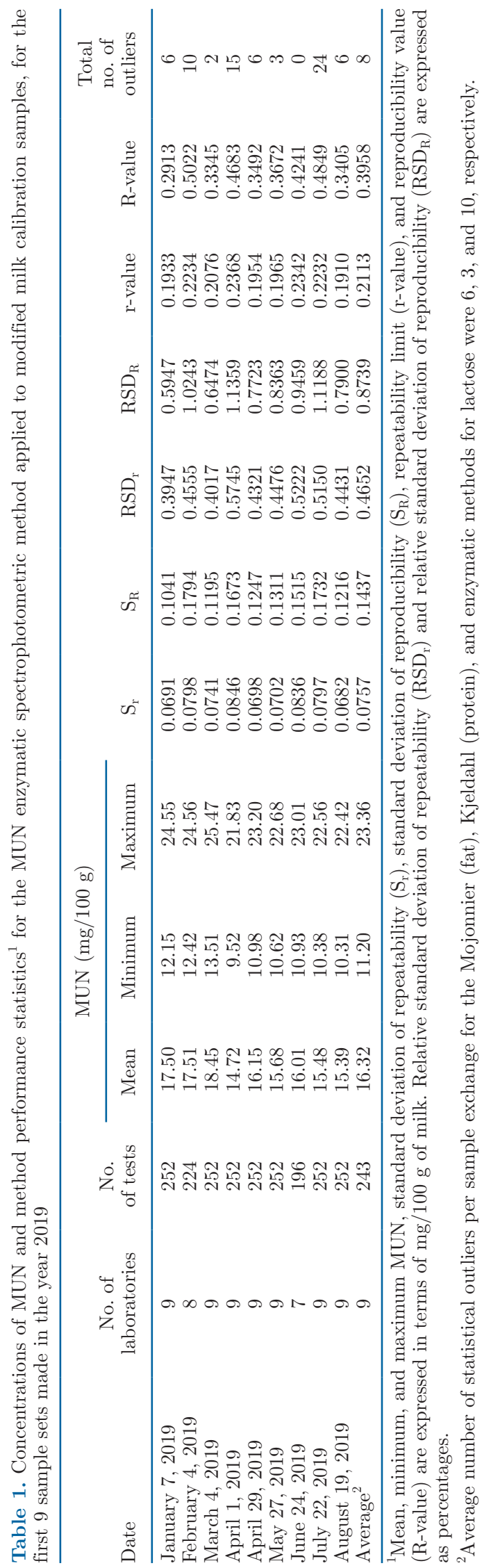

Journal of Dairy Science Vol. 104 No. 11, 2021 


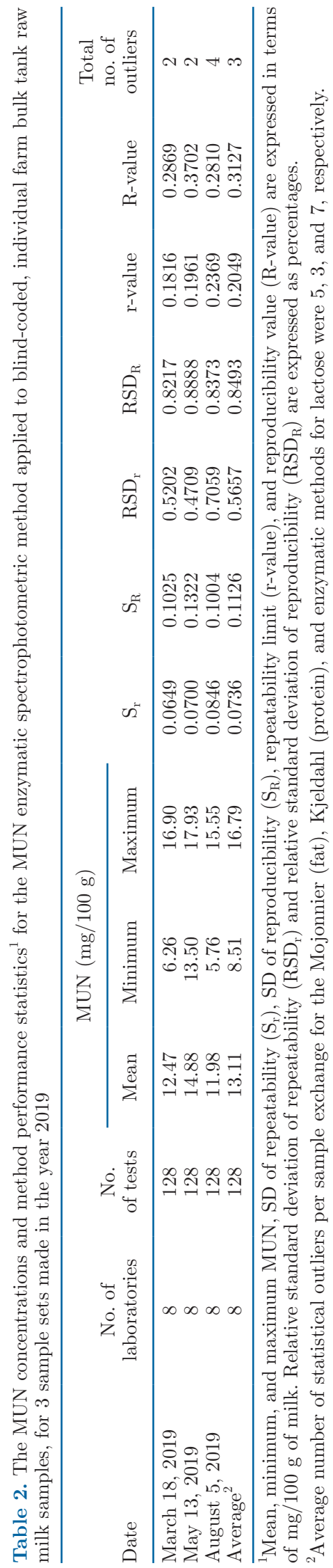

er $\mathrm{RSD}_{\mathrm{r}}$ and $\mathrm{RSD}_{\mathrm{R}}$ ) than the other reported chemical methods for measurement of MUN. The only reference that reported between laboratory reproducibility from results was the International Dairy Federation (IDF), Standard 195 (IDF, 2004). The IDF method, based on a differential $\mathrm{pH}$ measurement of an enzymatic hydrolysis of milk urea, had much higher values than the current study for $\mathrm{RSD}_{\mathrm{r}}$ (1.4 vs. $0.57 \%$, respectively) and $\mathrm{RSD}_{\mathrm{R}}$ (4.64 vs. $0.85 \%$, respectively).

The relative within and between laboratory method performance statistics for the validated official chemical reference testing of milk for fat, protein and lactose are shown in Table 4. The average $\mathrm{RSD}_{\mathrm{r}}$ and $\mathrm{RSD}_{\mathrm{R}}$ values for the spectrophotometric MUN method in the present study (Tables 1 and 2) are comparable to the average $\mathrm{RSD}_{\mathrm{r}}$ and $\mathrm{RSD}_{\mathrm{R}}$ values for chemical reference methods for measurement of the fat, protein, and lactose concentration in milk. Particularly, the lactose method reported in Table 4 (Lynch et al., 2007; AOAC International, 2019c; method 2006.06) is a very similar enzymatic spectrophotometric procedure to the MUN enzymatic spectrophotometric method reported in the current paper. Both methods involve enzymatic hydrolysis reactions, where $\mathrm{NADPH}$ or $\mathrm{NAD}^{+}$is oxidized or reduced, respectively, and the reduced form acts as the absorbing molecule during the UV-visible absorbance measurement. The materials and apparatus used and the steps performed for the 2 methods are very similar as well. Therefore, these 2 methods are a fair comparison. The $\mathrm{RSD}_{\mathrm{r}}$ and $\mathrm{RSD}_{\mathrm{R}}$ values for the lactose method and the average values for the MUN method are both very good (i.e., <1\%). Considering that the MUN concentration in milk is much lower than lactose, the RSD values for the MUN method were very good.

\section{Individual Laboratory Performances with the MUN Enzymatic Spectrophotometric Method Compared with All-Laboratory Mean Values}

Wojciechowski et al. (2016) described how individual laboratory analytical performance can be evaluated by comparing the data for each individual sample without statistical outliers removed to the all-laboratory mean reference value for each sample using residual difference plots. Examples of within laboratory performance of the enzymatic spectrophotometric method when analyzing the orthogonal design modified milk calibration samples and the blind-coded farm milk samples are shown in Figures 1 through 5. Residual plots of an individual laboratory's test result minus the all-laboratory mean for each sample plotted as a function of MUN concentration $(\mathrm{mg} / 100 \mathrm{~g}$ of milk) for 2 individual laboratories for one 14-sample set of the modified calibration milk set analyzed using the MUN enzymatic spectrophoto- 
Portnoy et al.: ENZYMATIC METHOD PERFORMANCE: MILK UREA NITROGEN
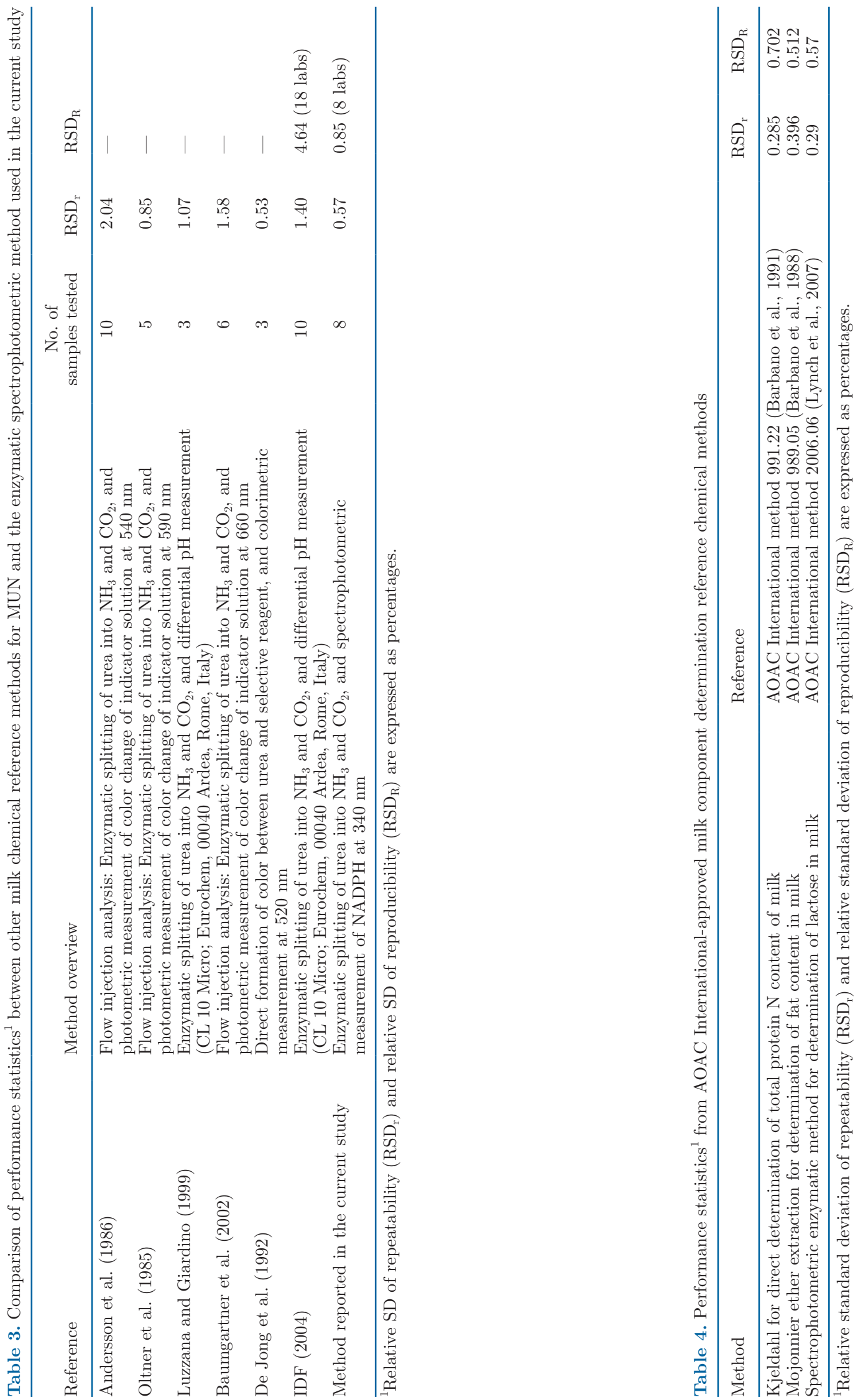
metric method are shown in Figures 1 and 2 for laboratories 1 and 2, respectively. In general, when the mean result for the 14 samples was lower or higher than the all-laboratory means, the residual plot showed a similar low or high bias, respectively, on all samples for that laboratory. Overall, the slopes of the regression plots of residual differences from all-laboratory mean reference value for individual labs were not significantly different $(P>0.05)$ than zero. Most of the bias for individual labs in this MUN determination method is likely due to differences in cuvette path length among laboratories, as each laboratory uses a different batch of disposable cuvettes. The path length determination done for each box of cuvettes (100 cuvettes per box) and the relative cuvette path length correction factor used for the calculation of MUN concentration, mentioned previously and described in detail by Lynch et al. (2007), tends to decrease this bias, but some residual bias can still be present due to the analytical uncertainty in determination of the relative pathlength correction for each box of cuvettes.

Residual plots of an individual laboratory's test result minus the all-laboratory mean for each sample plotted as a function of MUN concentration ( $\mathrm{mg} / 100 \mathrm{~g}$ milk) for 3 individual laboratories for a blind-duplicate set of 8 raw bulk tank farm milk samples analyzed using the MUN enzymatic spectrophotometric method are shown in Figures 3, 4, and 5 as a comparison to method performance on the modified milk samples shown in Figures 1 and 2. The distribution of the deviations from the all-laboratory mean for the individual farm milks were similar to those observed for the modified milks (Figures 1 and 2).

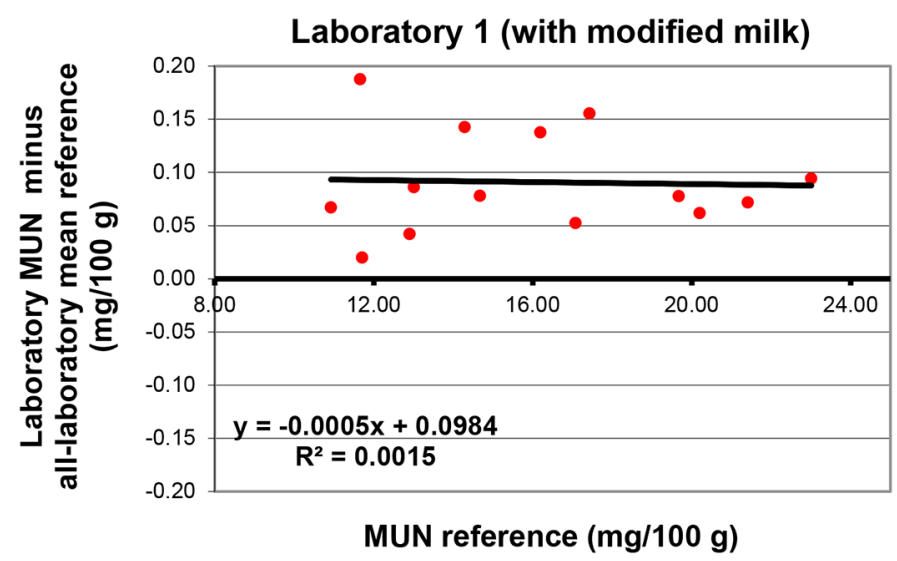

Figure 1. Residual plot of the differences (individual laboratory mean by sample minus all-laboratory mean) from the all-laboratory mean of the MUN enzymatic spectrophotometric result of laboratory 1 , as a function of the MUN content of the modified milk samples. The MUN content and difference from all-laboratory mean are expressed as mg of MUN/100 g of milk.
Laboratory 2 (with modified milk)

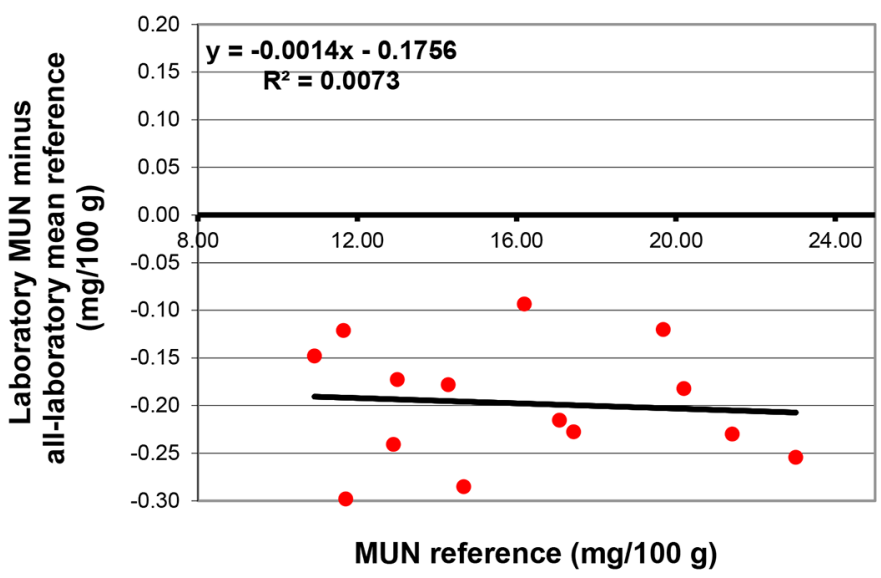

Figure 2. Residual plot of the differences (individual laboratory mean by sample minus all-laboratory mean) from the all-laboratory mean of the MUN enzymatic spectrophotometric result of laboratory 2 , as a function of the MUN content of the modified milk samples. The MUN content and difference from all-laboratory mean are expressed as mg of MUN/100 $\mathrm{g}$ of milk.

\section{CONCLUSIONS}

The relative within- $\left(\mathrm{RSD}_{\mathrm{r})}\right.$ and between- $\left(\mathrm{RSD}_{\mathrm{R}}\right)$ laboratory method values for the MUN enzymatic spectrophotometric method were $0.57 \%$ and $0.85 \%$, respectively, when testing individual farm milks. The spectrophotometric MUN method demonstrated better within and between laboratory performance than IDF differential $\mathrm{pH}$ MUN method with a much lower RSD (0.57 vs. $1.40 \%)$ and $\mathrm{RSD}_{\mathrm{R}}$ (0.85 vs $4.64 \%$ ). The spectrophotometric MUN method also had similar method
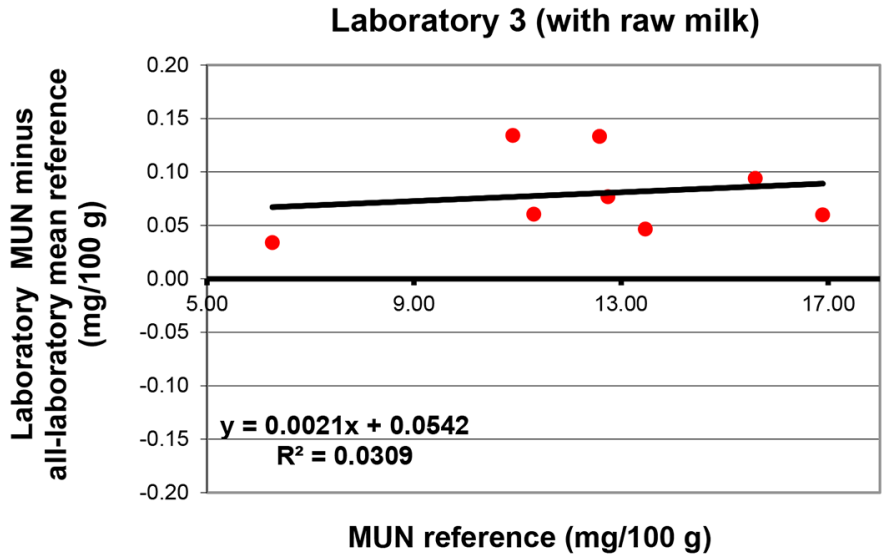

Figure 3. Residual plot of the differences (individual laboratory mean by sample minus all-laboratory mean) from the all-laboratory mean of the MUN enzymatic spectrophotometric result of laboratory 3 , as a function of the MUN content of the blind-coded, raw milk samples. The MUN content and difference from all-laboratory mean are expressed as mg of MUN/100 g of milk. 


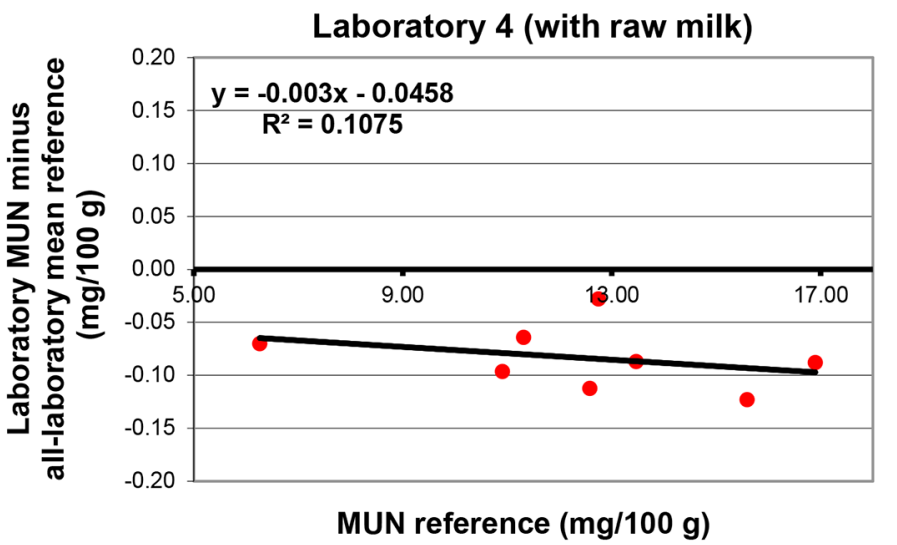

Figure 4. Residual plot of the differences (individual laboratory mean by sample minus all-laboratory mean) from the all-laboratory mean of the MUN enzymatic spectrophotometric result of laboratory 4 , as a function of the MUN content of the blind-coded, raw milk samples. The MUN content and difference from all-laboratory mean are expressed as mg of MUN/100 g of milk.

performance statistics as other AOAC International official chemical methods for primary milk component determinations, with the average of all $\mathrm{RSD}_{\mathrm{r}}$ and $\mathrm{RSD}_{\mathrm{R}}$ values being $<1 \%$. An official collaborative study of the enzymatic spectrophotometric MUN method to achieve IDF, AOAC International, or International Organization for Standardization official method status is needed.

\section{ACKNOWLEDGMENTS}

The authors thank all the USDA Federal Milk Market laboratories and affiliated laboratories for their

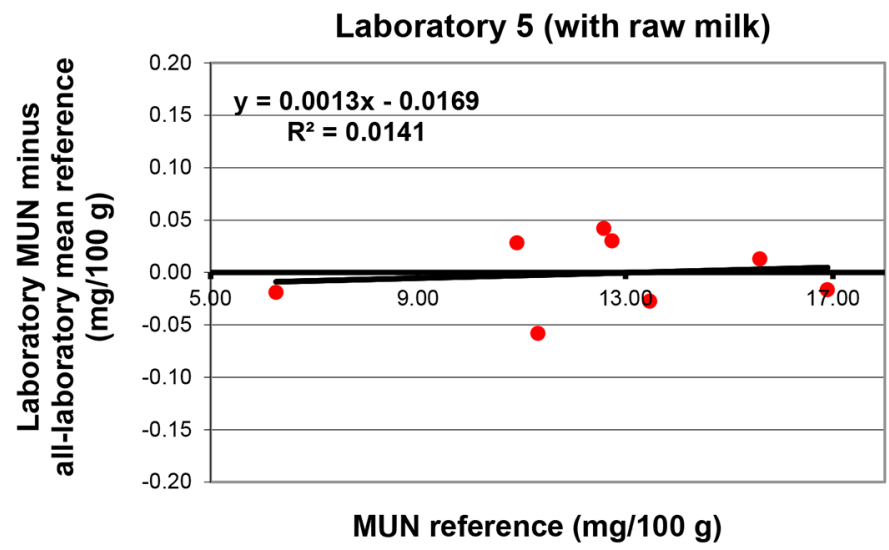

Figure 5. Residual plot of the differences (individual laboratory mean by sample minus all-laboratory mean) from the all-laboratory mean of the MUN enzymatic spectrophotometric result of laboratory 5 , as a function of the MUN content of the blind-coded, raw milk samples. The MUN content and difference from all-laboratory mean are expressed as mg of MUN/100 g of milk. collaboration and sample analysis in this work. The authors thank the Test Procedures Committee of the USDA, Dairy Programs, Federal Milk Markets for their financial support of this research. Use of names, names of ingredients, and identification of specific models of equipment is for scientific clarity and does not constitute any endorsement of product by authors, Cornell University, or the Northeast Dairy Foods Research Center. The authors have not stated any conflicts of interest.

\section{REFERENCES}

Andersson, G., L. Andersson, and G. Carlström. 1986. Determination of milk urea by flow injection analysis. J. Vet. Med. Series A. 33:53-58. https://doi.org/10.1111/j.1439-0442.1986.tb00505.x.

AOAC International. 2019a. Appendix D: Guidelines for collaborative study procedures to validate characteristics of a method of analysis. Official Methods of Analysis of AOAC International. AOAC International.

AOAC International. 2019b. Appendix F: Guidelines for standard method performance requirements. Official Methods of Analysis of AOAC International. AOAC International.

AOAC International. 2019c. Official Methods of Analysis. 21st ed. AOAC International.

Barbano, D. M., J. L. Clark, and C. E. Dunham. 1988. Comparison of Babcock and ether extraction methods for determination of fat content of milk: Collaborative study. J. Assoc. Off. Anal. Chem. 71:898-914. https://doi.org/10.1093/jaoac/71.5.898.

Barbano, D. M., J. M. Lynch, and J. R. Fleming. 1991. Direct and indirect determination of true protein content of milk by Kjeldahl analysis: collaborative study. J. Assoc. Off. Anal. Chem. 74:281288. https://doi.org/10.1093/jaoac/74.2.281.

Baumgartner, M., M. Flöck, P. Winter, W. Luf, and W. Baumgartner. 2002. Evaluation of flow injection analysis for determination of urea in sheep's and cow's milk. Acta Vet. Hung. 50:263-271. https: //doi.org/10.1556/avet.50.2002.3.2.

Broderick, G. A., and M. K. Clayton. 1997. A statistical evaluation of animal and nutritional factors influencing concentrations of milk urea nitrogen. J. Dairy Sci. 80:2964-2971. https://doi.org/10 .3168/jds.S0022-0302(97)76262-3.

Ciszuk, P., and T. Gebregziabher. 1994. Milk urea as an estimate of urine nitrogen of dairy cows and goats. Acta Agric. Scand. A Anim. Sci. 44:87-95. https://doi.org/10.1080/09064709409410187.

De Jong, E. A. M., H. Klomp, G. Ellen, and H. V. Hemert. 1992 Evaluation of a segmented-flow method for the routine determination of urea in milk. Neth. Milk Dairy J. 46:115-122.

Ferguson, J. D., and W. Chalupa. 1989. Impact of protein nutrition on reproduction in dairy cows. J. Dairy Sci. 72:746-766. https://doi .org/10.3168/jds.S0022-0302(89)79168-2.

Goulden, J. D. S. 1964. Analysis of milk by infra-red absorption. J. Dairy Res. 31:273-284. https://doi.org/10.1017/S0022029900018203.

Guo, K., E. Russek-Cohen, M. A. Varner, and R. A. Kohn. 2004. Effects of milk urea nitrogen and other factors on probability of conception of dairy cows. J. Dairy Sci. 87:1878-1885. https://doi .org/10.3168/jds.S0022-0302(04)73346-9.

Haaland, D. M., and E. V. Thomas. 1988. Partial least-squares methods for spectral analyses. 1. Relation to other quantitative calibration methods and the extraction of qualitative information. Anal. Chem. 60:1193-1202. https://doi.org/10.1021/ac00162a020.

Horwitz, W., P. Britton, and S. J. Chirtel. 1998. A simple method for evaluating data from an interlaboratory study. J AOAC Int $81: 1257-1266$

IDF (International Dairy Federation). 2004. Milk - Determination of urea content - Enzymatic method using difference in $\mathrm{pH}$ (Reference method). ISO 14637:2004. International Dairy Federation. 
Kauffman, A. J., and N. R. St-Pierre. 2001. The relationship of milk urea nitrogen to urine nitrogen excretion in Holstein and jersey cows. J. Dairy Sci. 84:2284-2294. https://doi.org/10.3168/jds S0022-0302(01)74675-9.

Kaylegian, K. E., D. A. Dwyer, J. M. Lynch, D. E. Bauman, J. R. Fleming, and D. M. Barbano. 2009. Impact of fatty acid composition on the accuracy of mid-infrared fat analysis of farm milks1. J. Dairy Sci. 92:2502-2513. https://doi.org/10.3168/jds.2008-1911.

Kaylegian, K. E., G. E. Houghton, J. M. Lynch, J. R. Fleming, and D. M. Barbano. 2006. Calibration of infrared milk analyzers: Modified milk versus producer milk. J. Dairy Sci. 89:2817-2832. https://doi .org/10.3168/jds.S0022-0302(06)72555-3.

Kohn, R. A., Z. Dou, J. D. Ferguson, and R. C. Boston. 1997. A sensitivity analysis of nitrogen losses from dairy farms. J. Environ. Manage. 50:417-428. https://doi.org/10.1006/jema.1997.0133.

Larson, S. F., W. R. Butler, and W. B. Currie. 1997. Reduced fertility associated with low progesterone post breeding and increased milk urea nitrogen in lactating cows. J. Dairy Sci. 80:1288-1295. https: //doi.org/10.3168/jds.S0022-0302(97)76058-2.

Lewis, D. 1957. Blood-urea concentration in relation to protein utilization in the ruminant. J. Agric. Sci. 48:438-446. https://doi.org/10 $.1017 /$ S0021859600032962.

Luzzana, M., and R. Giardino. 1999. Urea determination in milk by a differential $\mathrm{pH}$ technique. Lait 79:261-267. https://doi.org/10 .1051/lait:1999221.

Lynch, J. M. 1998. Use of AOAC International method performance statistics in the laboratory. J. AOAC Int. 81:679-684. https://doi .org/10.1093/jaoac/81.3.679.

Lynch, J. M., D. M. Barbano, and J. R. Fleming. 2007. Determination of the lactose content of fluid milk by spectrophotometric enzymatic analysis using weight additions and path length adjustment: Collaborative study. J. AOAC Int. 90:196-216.

Mitchell, R. G., G. W. Rogers, C. D. Dechow, J. E. Vallimont, J. B. Cooper, U. Sander-Nielsen, and J. S. Clay. 2005. Milk urea nitrogen concentration: Heritability and genetic correlations with reproductive performance and disease. J. Dairy Sci. 88:4434-4440. https://doi.org/10.3168/jds.S0022-0302(05)73130-1.
Nousiainen, J., K. J. Shingfield, and P. Huhtanen. 2004. Evaluation of milk urea nitrogen as a diagnostic of protein feeding. J. Dairy Sci. 87:386-398. https://doi.org/10.3168/jds.S0022-0302(04)73178-1.

Oltner, R., S. Bengtsson, and K. Larsson. 1985. Flow injection analysis for the determination of urea in cow's milk. Acta Vet. Scand. 26:396-404. https://doi.org/10.1186/BF03546539.

Portnoy, M., C. Coon, and D. M. Barbano. 2021. Infrared milk analyzers: Milk urea nitrogen calibration. J. Dairy Sci. 104:7426-7437. https://doi.org/10.3168/jds.2020-18772.

Rajala-Schultz, P. J., W. J. A. Saville, G. S. Frazer, and T. E. Wittum. 2001. Association between milk urea nitrogen and fertility in Ohio dairy cows. J. Dairy Sci. 84:482-489. https://doi.org/10.3168/jds .S0022-0302(01)74498-0.

Spek, J. W., J. Dijkstra, and A. Bannink. 2016. Influence of milk urea concentration on fractional urea disappearance rate from milk to blood plasma in dairy cows. J. Dairy Sci. 99:3880-3888. https:// doi.org/10.3168/jds.2015-9421.

Spek, J. W., J. Dijkstra, G. van Duinkerken, W. H. Hendriks, and A. Bannink. 2013. Prediction of urinary nitrogen and urinary urea nitrogen excretion by lactating dairy cattle in northwestern Europe and North America: A meta-analysis. J. Dairy Sci. 96:4310-4322. https://doi.org/10.3168/jds.2012-6265.

Wojciechowski, K. L., C. Melilli, and D. M. Barbano. 2016. A proficiency test system to improve performance of milk analysis methods and produce reference values for component calibration samples for infrared milk analysis. J. Dairy Sci. 99:6808-6827. https:/ /doi.org/10.3168/jds.2016-10936.

\section{ORCIDS}

M. Portnoy () https://orcid.org/0000-0002-8448-5855

C. Coon (ㄱ) https://orcid.org/0000-0002-3576-3249

D. M. Barbano (®) https://orcid.org/0000-0002-0206-7028 